\title{
VARIATION OF STOMATAL CONDUCTANCE AND ITS CONTROLLING FACTORS OF DIFFERENT SPECIES IN A WET EVERGREEN FOREST IN THE MID-COUNTRY WET ZONE OF SRI LANKA
}

\author{
W A J M De Costa and A G Chandrapala \\ Department of Crop Science, University of Peradeniya
}

Stomatal conductance is a primary determinant of the net carbon balance and growth of different plant species in a forest community. Because of its influence on transpirational water loss, stomatal conductance determines the water balance of a plant. As both carbon and water balances play important roles in survival and establishment of seedlings of different plant species in a forest community, stomatal conductance has a direct influence on species composition and succession of a forest. Therefore, the main objective of the present study was to describe the inter-species variation of stomatal conductance in a wet, evergreen forest in the mid-country wet zone of Sri Lanka. A secondary objective was to examine the variation of two parameters which could influence stomatal opening, namely incident light intensity and leaf temperature, and to see whether any direct correlations can be established between stomatal conductance and the above parameters.

This study was conducted in the Gannoruwa forest reserve in Kandy in September, 1997. 108 plant species which included all growth forms (i.e. trees, shrubs, herbaceous plants, vines and grasses) were found. Stomatal conductance was measured using a portable diffusion porometer which also recorded the incident light intensity ( in terms of photosynthetically-active radiation) and leaf temperature. Conductances of both upper and lower leaf surfaces were measured and total leaf conductance was obtained by summing the two above measurements. In a given species, at least three plants were sampled.

There were significant differences between species in lower surface conductance $\left(\mathrm{g}_{1}\right)$, upper surface conductance $\left(g_{u}\right)$ and total leaf conductance $(g)$. Except in one species, $g_{l}$ was greater than $g_{u}$ in all other species examined. Lower Surface Conductance $\left(\mathrm{g}_{1}\right)$ ranged from 17 to $1280 \mathrm{mmol} \mathrm{m} \mathrm{m}^{-2} \mathrm{~s}^{-1}$ with a mean of $175.8+=8.9 \mathrm{mmol} \mathrm{m}^{-2} \mathrm{~s}^{-1}$ whereas gu ranged from 2.36 to $252 \mathrm{mmol} \mathrm{m}^{-2} \mathrm{~s}^{-1}$ with a mean of $25.15+=1.58 \mathrm{mmol} \mathrm{m}^{-2} \mathrm{~s}^{-1}$. The range of total conductance $(\mathrm{g})$ was $20.45-1309.8 \mathrm{mmol} \mathrm{m}^{-2} \mathrm{~s}^{-1}$ with a mean of $201.41+=9.44 \mathrm{mmol} \mathrm{m}^{-2} \mathrm{~s}^{-1}$. The frequency distributions of atl three conductance parameters (i.e. lower, upper and total) were skewed to the left with the respective median values being 132.5 (for $\mathrm{g}_{1}$ ), $18.25\left(\mathrm{~g}_{\mathrm{u}}\right)$ and $149.9(\mathrm{~g}) \mathrm{mmol} \mathrm{m}^{-2} \mathrm{~s}^{-1}$. Normality of the distributions when tested using the box plot technique, showed significant skewness to the left. Deletion of extreme values did not improve normality significantly.

The light intensities experienced by the leaves ranged from 2.5 to $1830 \mu \mathrm{mol}$ (PAR) $\mathrm{m}^{-2} \mathrm{~s}^{-1}$ and the leaf temperatures ranged from 24.55 to $34.4^{\circ} \mathrm{C}$. When all species were considered together, total leaf stomatal conductance $(\mathrm{g})$ had a significant positive correlation with light intensity. But, there was no significant correlation between $g$ and leaf temperature. Similar results were obtained when lower and upper surface conductances were considered separately as well. There was a highly significant positive correlation between light intensity and leaf temperature. A multiple regression analysis showed that these two variables explained only $8 \%$ of the overall variation of leaf stomatal conductance. This infers species differences, interactions between species, and their response to variations in light intensity and leaf temperature are more significant. Stomatal conductance of different species respond in different degrees to light and temperature variations.

A cluster analysis allowed the 108 plant species examined to be grouped in to different categories on the basis of their total leaf stomatal conductance $(\mathrm{g})$. The different species groups could be broadly related to their position in the successional sequence. It was found that the species established under the canopy on the forest floor generally had lower levels of $\mathrm{g}$ than those establishing in canopy gaps. While many species of the latter group (growing in gaps) had the ability to raise their stomatal conductance in response to increasing light intensity, most species of the former group (growing under the canopy shade) could not respond to the occasional sunflecks that are incident on them at different times of the day.

Proceedings of the Third Ammual Forestry Symposium 1997, of the Department of Forestry and Environmental Science, University of Sri Jayewardenepura, Sri Lanka 